\title{
Effect of miRNA-203 on cervical cancer cells and its underlying mechanism
}

\author{
X.Z. Yin", ${ }^{1,2}$ D.M. Zhao ${ }^{3}$, G.X. Zhang ${ }^{1}$ and L. Liu ${ }^{2}$ \\ ${ }^{1}$ College of Animal Science and Technology, Northeast Agricultural University, \\ Harbin, China \\ ${ }^{2}$ College of Basic Medical Sciences, Jamusi University, Jamusi, China \\ ${ }^{3}$ The First Affiliated Hospital of Jiamusi University, Jiamusi, China \\ Corresponding authors: G.X. Zhang / L. Liu \\ E-mail: hangguixue898@126.com / liuleilive@yeah.net
}

Genet. Mol. Res. 15 (3): gmr.15038680

Received March 31, 2016

Accepted June 13, 2016

Published September 23, 2016

DOI http://dx.doi.org/10.4238/gmr.15038680

Copyright $(2016$ The Authors. This is an open-access article distributed under the terms of the Creative Commons Attribution ShareAlike (CC BY-SA) 4.0 License.

\begin{abstract}
RNA-203 is involved in the development and progression of various types of cancer. However, its role in cervical cancer remains unclear. The aim of this study was to investigate the effect of miRNA-203 on the proliferation and migration of HeLa cervical cancer cells, as well as survivin expression in these cells. A miRNA-203 primer probe was designed according to a sequence obtained from NCBI. The expression of miRNA-203 in cervical epithelial cells and cervical cancer cells was detected by quantitative reverse transcriptase-polymerase chain reaction. The miRNA-203 expression pattern was compared between these two cell lines. The cervical cancer cells were transfected with miRNA-203 mimic or inhibitor to determine their effects on proliferation and migration. The expression of the miRNA-203 target protein (survivin) was analyzed by western blot. Cervical cancer cells showed reduced miRNA-203 expression compared to cervical epithelial cells. Transfection of miRNA-203
\end{abstract}


mimic upregulated the expression of miRNA-203, suppressed cell proliferation and migration, and downregulated survivin expression $(\mathrm{P}<0.05)$. However, downregulation of miRNA-203 expression did not affect proliferation, migration, and survivin expression in cervical cancer cells $(\mathrm{P}>0.05)$. In conclusion, upregulation of miRNA-203 in cervical cancer cells inhibits the proliferative and migratory capacities of these cells by downregulating the expression of survivin.

Key words: Cervical cancer; Survivin; miRNA-203; Proliferation; Migration

\section{INTRODUCTION}

Cervical cancer is one of the most common types of cancer affecting women worldwide (Schmid and Oehler, 2015; Yang et al., 2015). It is among the top three malignant cancers, and has the fifth highest mortality rate (7.3\%) in both men and women. Approximately $20 \%$ of all cancer-related deaths can be attributed to cervical cancer. A larger number of youths have been afflicted with this type of cancer over the past few years. It also accounts for $75-80 \%$ of all cancers in developing countries. Locally, there has been an increase in the incidence of cervical cancer, especially in the youth, which has a serious impact on human health (Zeng et al., 2015).

A number of studies are currently attempting to elucidate the pathogenesis of cervical cancer; however, its underlying molecular mechanism remains unclear. Therefore, further research into the pathogenesis of cervical cancer is of paramount importance (Chen et al., 2013). A majority of the research into the pathogenesis of cervical cancer is focused on human papilloma virus (HPV) infection-induced cervical cancer. Previous studies have suggested that HPV disrupts the cell cycle by inserting itself into the host cell genome and inducing genetic mutations, resulting in the development of cervical cancer (Chintharlapalli et al., 2011). Previous studies have also demonstrated the important role of cell apoptosis in the initiation and development of cervical cancer. The imbalance between oncogenes and antioncogenes induces an over-expression in oncogenes, which in turn transforms normal cells to cancerous cells, ultimately resulting in cervical cancer. Cell adhesive factors play an important role in cell cycle, and the changes in expression of these factors are mainly responsible for the pathogenesis of cancer (Debeb et al., 2010). Taken together, these studies indicate that abnormalities or imbalances in the expression of genes related to the pathogenesis of cervical cancer could induce the development and progression of this disease. Therefore, specific gene expression and its modulatory behavior must be elucidated in order to provide a theoretical basis for the pathogenesis of cervical cancer.

Recent studies have focused on exploring the role of microRNA (miRNA) in cancer. miRNA are small RNA molecules that modulate gene expression post-transcription. Studies have shown that miRNA are abnormally expressed in cancer. miRNA participate in the tumor cell differentiation, proliferation, and apoptosis processes (Gaca et al., 2012; Ji et al., 2012; Jin et al., 2013; Huang et al., 2014; Liu et al., 2015). A previous report suggested that miRNA-203 plays an important role in the pathogenesis of many types of cancer (Kapinas et al., 2015). In this study, we investigated the role of miRNA-203 in cervical cancer, based on previous related studies, in order to explore the modulatory mechanism of miRNA in cervical cancer, and provide a theoretical basis for the pathogenesis and targeted therapy of cervical cancer.

Genetics and Molecular Research 15 (3): gmr.15038680 


\section{MATERIAL AND METHODS}

\section{Reagents}

Cervical epithelial cells and cervical cancer cells were purchased from ATCC (Manassas, VA, USA). The qRT-PCR pre-mix and RNA isolation kit were purchased from Promega (Madison, WI, USA) and the cell transfection reagents were purchased from Yingjun (Shanghai, China). Cell culture media RPMI1640 and PS were purchased from Gibco (Waltham, MA, USA) and Biyuntian (Beijing, China), respectively. The antibody against survivin and the secondary antibody were purchased from Santa Cruz (Dallas, TX, USA). The remaining reagents were also purchased from Biyuntian. The primers were synthesized and the genes were detected by Yinjun.

\section{Cell culture and transfection}

HeLa cells (stored in liquid nitrogen) were thawed, incubated at $37^{\circ} \mathrm{C}$ for $5 \mathrm{~min}$, and transferred to sterile $1.5-\mathrm{mL}$ EP tubes in a biosafety unit. The cells were centrifuged at $500 \mathrm{~g}$ for $3 \mathrm{~min}$, the supernatant was removed, and the cell pellet was suspended in fresh complete 1640 medium with $10 \%$ fetal bovine serum. The cells were counted using $10 \mu \mathrm{L}$ cell suspension. The cells were then cultured on dishes at a concentration of $5 \times 10^{6}$ cells/ dish at $37^{\circ} \mathrm{C}$ and under $5 \% \mathrm{CO}_{2}$ for $24 \mathrm{~h}$. Cells at a confluence rate of $85 \%$ were transfected with the miRNA-203 mimic (GUGAAAUGUUUAGGACCACUAG), miRNA-203 inhibitor (GUGAAAUGUUUAGGACCACUAG), or the control (UCACAACCUCCUAGAAAGAGU AGA) synthesized by SwitchGear Genomics (Carlsbad, CA, USA) using Lipo2000 (Biyuntian) according to the manufacturer instructions. Accordingly, the cells were separated into the blank control, mimic, and inhibitor groups. Each group contained three replicates.

\section{Effect of miRNA-203 on cervical cancer cell proliferation}

The HeLa cells were transfected with miRNA-203 for 24,48 , and $72 \mathrm{~h}$. The proliferative capacity of transfected HeLa cells was analyzed using the MTT method (Biyuntian) according to manufacturer protocol, using cells cultured in normal medium as the negative control. The absorbance of the cells was detected at an optical density of $490 \mathrm{~nm}$. The cell proliferation rate was calculated using the following equation:

Proliferation rate $=\frac{(O D \text { of the control group }-O D \text { of the experimental group })}{(O D \text { of the control group })} \times 100 \%$

\section{Effects of miRNA-203 on cervical cancer cell migration}

The effect of miRNA-203 on the migratory ability of cervical cancer cells was determined by a wound healing assay. HeLa cells were cultured on six-well plates with fresh complete medium at a concentration of $1 \times 10^{5}$ cells/well for $24 \mathrm{~h}$. The cells were "wounded" (area without cell growth) with a sterile pipette tip. The cell debris was washed with PBS and the cells were transfected with the miRNA-203 mimic or inhibitor using Lipofectamine 2000. The cells were cultured, and the wound distance between cells was detected at 24, 48, and 72 $\mathrm{h}$. Each cell group was analyzed in triplicate and the average value was used.

Genetics and Molecular Research 15 (3): gmr.15038680 


\section{Effect of miRNA-203 on survivin expression in cervical cancer cells}

The survivin RNA and protein was isolated from cervical cancer cells incubated for $24 \mathrm{~h}$, using standard RNA and protein isolation kits. Survivin RNA and protein expression in miRNA-203-transfected cervical cancer cells was measured by quantitative reverse transcriptase-polymerase chain reaction (qRT-PCR) and western blot. The reaction mixture was composed of $10 \mu \mathrm{L}$ qRT-PCR Mix, $0.8 \mu \mathrm{L}$ forward primer, $0.8 \mu \mathrm{L}$ reverse primer, $1.0 \mu \mathrm{g}$

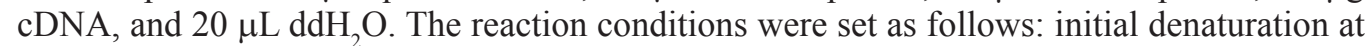
$95^{\circ} \mathrm{C}$ for $3 \mathrm{~min}$; 40 cycles of denaturation at $95^{\circ} \mathrm{C}$ for $10 \mathrm{~s}$ and amplification at $60^{\circ} \mathrm{C}$ for $30 \mathrm{~s}$; and a final amplification at $55^{\circ} \mathrm{C}$ for $10 \mathrm{~s}$. Western blot analysis was performed using primary and secondary antibodies diluted to 1:500 and 1:1000, respectively.

\section{RESULTS}

\section{Effect of miRNA-203 on the proliferative ability of cervical cancer cells}

Cervical cancer cells transfected with the miRNA-203 mimic showed significantly downregulated proliferation, compared to cells in the control and inhibition groups $(\mathrm{P}<0.05)$. However, the cells in the control and inhibition groups showed no significant differences ( $\mathrm{P}$ $>0.05$ ). miRNA-203 over-expression could inhibit the proliferation of HeLa cervical cancer cells (Figure 1).

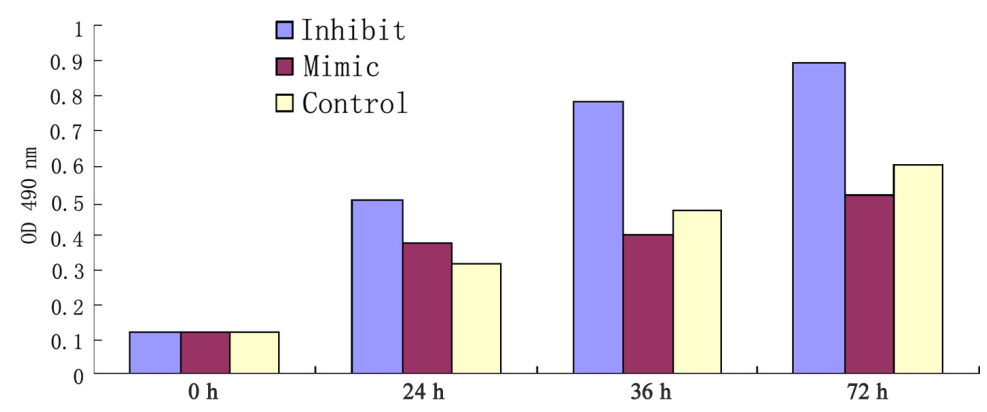

Figure 1. Proliferation ability of Hela cells.

\section{Effect of miRNA-203 on cervical cancer cell migration}

The effect of miRNA-203 expression on the migration ability of cervical cancer cells was determined by a wound healing assay. The wound distance was measured at 24,48 , and 72 $\mathrm{h}$ and three replicates were made for each group. The results of this experiment, summarized in Table 1, indicate that the upregulation of miRNA-203 significantly inhibits cervical cancer cell migration, while its downregulation had no effect on the cell migration.

\section{Effect of miRNA-203 on survivin expression in cervical cancer cells}

The expression of miRNA-203 in each group is summarized in Table 2. Transfection of miRNA-203 mimic or inhibitor resulted in a significant increase or decrease in miRNA-203 
expression in the cervical cancer cells. Moreover, we observed that survivin expression corresponded with mi-RNA-203 expression; that is, variations in miRNA expression induced a change in survivin expression (Figure 2).

Table 1. Cervical cancer cell migration (wound healing assay).

\begin{tabular}{|c|c|c|c|c|}
\hline Groups & $0 \mathrm{~h}$ & $24 \mathrm{~h}$ & $48 \mathrm{~h}$ & $72 \mathrm{~h}$ \\
\hline miRNA-203 mimic $(\mu \mathrm{m})$ & 35 & 35.12 & 35.2 & 35.34 \\
\hline miRNA-203 inhibitor $(\mu \mathrm{m})$ & 35 & 34.24 & 15.88 & 10.34 \\
\hline Control $(\mu \mathrm{m})$ & 35 & 30.02 & 13.36 & 5.78 \\
\hline $\mathrm{P}$ value & $>0.05$ & $<0.05$ & $<0.05$ & $<0.05$ \\
\hline
\end{tabular}

Table 2. MicroRNA-203 expression in each group of cervical cancer cells.

\begin{tabular}{l|c|c|c|c}
\hline Groups & $0 \mathrm{~h}$ & $24 \mathrm{~h}$ & $48 \mathrm{~h}$ & $72 \mathrm{~h}$ \\
\hline Mimic & $1.51 \pm 0.31$ & $4.67 \pm 0.58$ & $6.47 \pm 0.79$ & $8.45 \pm 1.34$ \\
\hline Inhibit & $1.43 \pm 0.24$ & $1.76 \pm 0.34$ & $3.04 \pm 0.34$ & $3.66 \pm 0.24$ \\
\hline Control & $1.38 \pm 0.15$ & $2.25 \pm 0.34$ & $3.65 \pm 0.34$ & $4.45 \pm 0.36$ \\
\hline P value & $>0.05$ & $<0.05$ & $<0.05$ & $<0.05$ \\
\hline
\end{tabular}

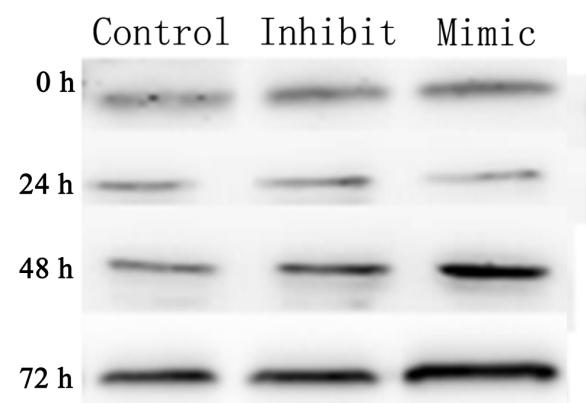

Figure 2. Expression of survivin in each group.

\section{DISCUSSION}

miRNA is a non-coding, 22-25 nucleotide-long, single-stranded RNA. miRNA employs two different mechanisms to bind with the target genes because of complementary base paring. Previous studies have shown that miRNA plays a major role in various cell functions, such as cell metabolism, cell proliferation, cell differentiation, and apoptosis. miRNA has been reported to specifically bind to mRNA and negatively modulate target gene expression. It participates in tumor pathogenesis by modulating the tumor-promoting as well as tumorinhibitory genes (Saini et al., 2011; Ma et al., 2013). A complete match between miRNA and the mRNA results in degradation of the mRNA. Incomplete binding of miRNA with the 5'-UTR, 3'-UTR, or CDS post-transcription inhibits gene expression, which in turn leads to a decrease in protein expression (Shen et al., 2012; Chen et al., 2013; Singh and Chakrabarty, 2013; Weirauch et al., 2013). Incomplete matching of the miRNA with mRNA is known to modulate the expression of several proteins. In contrast, a protein can also be modulated by various miRNA (Wu et al., 2014; Yu et al., 2014). The technology for miRNA research is currently well established and its modulatory role in human disease has been identified. This

Genetics and Molecular Research 15 (3): gmr.15038680 
has led to the use of miRNA as clinical biomarkers for early-stage tumor detection and as markers for targeted therapy (Yuan et al., 2015). Therefore, elucidating the modulatory role of miRNA in disease-related genes will provide evidence for disease pathogenesis as well as targets for clinical therapy (Zhang et al., 2012, 2013).

In this study, survivin expression was analyzed as it belongs to the IAP family, which has recently been cloned. Survivin participates in the cell cycle, and is expressed specifically in the $\mathrm{G} 2 / \mathrm{M}$ phase. The promoter region of survivin presents a sequence similar to that of the cell cycle-dependent complex. Previous studies have reported that survivin is specifically expressed in tumor tissues. Therefore, it could be an ideal therapeutic target for tumor, which would provide novel avenues for tumor treatment. Previous studies have also reported a close association between survivin gene expression and the pathogenesis of various types of tumors. The changes in survivin expression directly affect tumor radiation therapy. Patients with differing survivin gene expressions present different responses to radiation therapy. Moreover, the change in survivin expression is a major criterion for tumor diagnosis. However, we cannot exclude the involvement of other miRNA-203 target genes, such as $c$-jun and p63, in the pathogenesis of cervical cancer; in fact, the major limitation of this study is that the expressions of $c$-jun and $p 63$ were not measured after transfection with the miRNA-203 mimic and the inhibitor.

In this study, we determined the changes in miRNA-203 expression in cervical cancer cells, and its effects on the proliferation and migration of cervical cancer cells. We discovered that the expression of survivin in cervical cancer cells is modulated by miRNA-203 in combination with the changes in survivin gene expression, which in turn inhibits the proliferation of cervical cancer cells. These results indicated that survivin expression might be correlated with the effects of miRNA-203 on cervical cancer. Therefore, it is essential to investigate its expression and effect on cervical cancer cells. Cervical cancer diagnosis mainly includes techniques such as pathological examination, viral DNA detection, and identification of biomarkers in plasma; the results of this study could further supplement current biomarker detection methods for cervical cancer diagnosis.

\section{Conflicts of interest}

The authors declare no conflict of interest.

\section{ACKNOWLEDGMENTS}

We would like to thank the anonymous reviewers for reviewing this manuscript.

\section{REFERENCES}

Chen Y, Tsai YH and Tseng SH (2013). Inhibition of cyclin-dependent kinase 1-induced cell death in neuroblastoma cells through the microRNA-34a-MYCN-survivin pathway. Surgery 153: 4-16. http://dx.doi.org/10.1016/j. surg.2012.03.030

Chintharlapalli S, Papineni S, Lei P, Pathi S, et al. (2011). Betulinic acid inhibits colon cancer cell and tumor growth and induces proteasome-dependent and -independent downregulation of specificity proteins ( $\mathrm{Sp}$ ) transcription factors. BMC Cancer 11: 371.http://dx.doi.org/10.1186/1471-2407-11-371

Debeb BG, Zhang X, Krishnamurthy S, Gao H, et al. (2010). Characterizing cancer cells with cancer stem cell-like features in 293T human embryonic kidney cells. Mol. Cancer 9: 180.http://dx.doi.org/10.1186/1476-4598-9-180

Gaca S, Reichert S, Rödel C, Rödel F, et al. (2012). Survivin-miRNA-loaded nanoparticles as auxiliary tools for radiation therapy: preparation, characterisation, drug release, cytotoxicity and therapeutic effect on colorectal cancer cells. $J$. Microencapsul. 29: 685-694. http://dx.doi.org/10.3109/02652048.2012.680511

Genetics and Molecular Research 15 (3): gmr.15038680 
Huang J, Lyu H, Wang J and Liu B (2014). MicroRNA regulation and therapeutic targeting of survivin in cancer. Am. J. Cancer Res. 5: 20-31.

Ji X, Wang Z, Geamanu A, Goja A, et al. (2012). Delta-tocotrienol suppresses Notch-1 pathway by upregulating miR-34a in nonsmall cell lung cancer cells. Int. J. Cancer 131: 2668-2677. http://dx.doi.org/10.1002/ijc.27549

Jin J, Deng J, Wang F, Xia X, et al. (2013). The expression and function of microRNA-203 in lung cancer. Tumour Biol. 34: 349-357.http://dx.doi.org/10.1007/s13277-012-0556-3

Kapinas K, Kim H, Mandeville M, Martin-Buley LA, et al. (2015). microRNA-mediated survivin control of pluripotency. J. Cell. Physiol. 230: 63-70. http://dx.doi.org/10.1002/jcp.24681

Liu P, Xin F and Ma CF (2015). Clinical significance of serum miR-196a in cervical intraepithelial neoplasia and cervical cancer. Genet. Mol. Res. 14: 17995-18002.http://dx.doi.org/10.4238/2015.December.22.25

Ma Q, Wang X, Li Z, Li B, et al. (2013). microRNA-16 represses colorectal cancer cell growth in vitro by regulating the p53/survivin signaling pathway. Oncol. Rep. 29: 1652-1658.

Saini S, Yamamura S, Majid S, Shahryari V, et al. (2011). MicroRNA-708 induces apoptosis and suppresses tumorigenicity in renal cancer cells. Cancer Res. 71: 6208-6219. http://dx.doi.org/10.1158/0008-5472.CAN-11-0073

Schmid BC and Oehler MK (2015). Improvements in progression-free and overall survival due to the use of anti-angiogenic agents in gynecologic cancers. Curr. Treat. Options Oncol. 16: 318. http://dx.doi.org/10.1007/s11864-014-0318-0

Shen Z, Zhan G, Ye D, Ren Y, et al. (2012). MicroRNA-34a affects the occurrence of laryngeal squamous cell carcinoma by targeting the antiapoptotic gene survivin. Med. Oncol. 29: 2473-2480. http://dx.doi.org/10.1007/s12032-011-0156-x

Singh N and Chakrabarty S (2013). Induction of CaSR expression circumvents the molecular features of malignant CaSR null colon cancer cells. Int. J. Cancer 133: 2307-2314. http://dx.doi.org/10.1002/ijc.28270

Weirauch U, Beckmann N, Thomas M, Grünweller A, et al. (2013). Functional role and therapeutic potential of the pim-1 kinase in colon carcinoma. Neoplasia 15: 783-794. http://dx.doi.org/10.1593/neo.13172

Wu Y, Guo L, Liu J, Liu R, et al. (2014). The reversing and molecular mechanisms of miR-503 on the drug-resistance to cisplatin in A549/DDP cells. Zhongguo Fei Ai Za Zhi 17: 1-7.

Yang Q, Zhou X, Zhang M, Bi L, et al. (2015). Angel of human health: current research updates in toad medicine. Am. J. Transl. Res. 7: 1-14.

Yu QQ, Wu H, Huang X, Shen H, et al. (2014). MiR-1 targets PIK3CA and inhibits tumorigenic properties of A549 cells. Biomed. Pharmacother. 68: 155-161.http://dx.doi.org/10.1016/j.biopha.2014.01.005

Yuan J, Xiao G, Peng G, Liu D, et al. (2015). MiRNA-125a-5p inhibits glioblastoma cell proliferation and promotes cell differentiation by targeting TAZ. Biochem. Biophys. Res. Commun. 457: 171-176. http://dx.doi.org/10.1016/j. bbrc.2014.12.078

Zeng XT, Leng WD, Zhang C, Liu J, et al. (2015). Meta-analysis on the association between toothbrushing and head and neck cancer. Oral Oncol. 51: 446-451.http://dx.doi.org/10.1016/j.oraloncology.2015.02.095

Zhang N, Li X, Wu CW, Dong Y, et al. (2013). microRNA-7 is a novel inhibitor of YY1 contributing to colorectal tumorigenesis. Oncogene 32: 5078-5088. http://dx.doi.org/10.1038/onc.2012.526

Zhang Y, Wei W, Cheng N, Wang K, et al. (2012). Hepatitis C virus-induced up-regulation of microRNA-155 promotes hepatocarcinogenesis by activating Wnt signaling. Hepatology 56: 1631-1640. http://dx.doi.org/10.1002/hep.25849

Genetics and Molecular Research 15 (3): gmr.15038680 